POSTGRAD. MED. J., (1966), 42, 86

Case Reports

\title{
ANOREXIA NERVOSA IN AN IDENTICAL TWIN
}

\author{
A. CrisP, D.P.M., M.R.C.P \\ Academic Psychiatric Unit, Middlesex Hospital, \\ London, W.1.
}

RECENT papers (Crisp 1965a, 1965b, Russell 1964, 1965) have been concerned with the possible interrelation and significance of hypothalamic, peripheral metabolic and psychological factors for the genesis of anorexia nervosa. As a clinical phenomenon, anorexia nervosa is a fairly discrete entity and Bliss and Branch (1960) have attributed this mainly to the uniform symptomatology characteristic of "nervous malnutrition". They propose that this psychobiological posture can have a variety of social and psychological determinants. Other workers agree that anorexia nervosa can be subdivided usefully into primary and secondary forms and that the primary form may again merit subdivision (Meyer 1961, King 1963). More recently Crisp (1965b) has suggested that "typical" anorexia nervosa is characterised by certain premorbid nutritional features which may have family "psychosomatic" determinan'ts and implications. Moreover, the disorder often seems to arise through overdetermination of dieting behaviour which has become inadvertently incorporated during adolescence into resolving intense postpubertal emotional conflict. Any genetic basis the disorder has, so far as its nutritional nature is concerned, is at least as likely to contribute to the premorbid metabolic and nutritional "set", which is often one associated with over-nutrition, as to the disorder itself. In this connection it has been suggested (Crisp 1965b) that the anorexia nervosa proband is already nutritionally different at birth from her sister siblings but that this difference may in part be due to differences in intrauterine nutrition which are not themselves genetically determined.

Only one report of anorexia nervosa in presumed identical twins (i.e. the sibs were of the same age and sex and looked identical) has been found in the literature (Meyer 1961). These twins were initially conoordant for the disorder but later one of the twins recovered. They were raised together and are reported on as having had very similar environmental experiences in childhood. During childhood they were both well nourished and they had early and concordant menarches around the age of 12. Their illnesses developed simultaneously at the ages of 17 when they both underwent similar unhappy experiences. The twin who recovered was reported on as having begun to make a heterosexual adjustment as her illness remitted. Soon afterwards she married, remained clinically well, and now has two children. The other twin's symptoms became more entrenched at this time of separation and her life situation remained severely restricted. She was considered by some psychiatrists to have developed schizophrenia. However, Meyer believes that the illness had merely taken on the features of chronic anorexia nervosa and, from the description of the case, this would seem to be so. This case report suggests that environmental determinants of the disorder may be important since initial concordance was associated not only with presumed identical genetic endowment but also with identical upbringing, while the twins' ultimate capacity for discordance for anorexia nervosa was revealed during a time in which their life situations and experiences diverged. It cannot be concluded from this case report however, that this latter phenomenon was necessarily causal to the remission of the illness. The present author has also heard of two other female patients with anorexia nervosa who are presumed identical twins and who are discordant for anorexia nervosa. In the first of these cases (Tibbetts 1965) the proband is said to have developed her illness at the time 
TABLE 1

ZYGOSITY DATA

\begin{tabular}{l|c|c}
\hline & Proband & Co-Twin \\
\hline Sex & Female & Female \\
Height & $5^{\prime} 4 \frac{1}{2}{ }^{\prime}$ & $5^{\prime} 5^{\prime \prime}$ \\
Androgyny Score & 80 & 78 \\
Eye Colour & Blue & Blue \\
PTC taste test & Taster (Solution 9) & Taster (Solution 9) \\
Handedness & Right & Right \\
\hline
\end{tabular}

EEG

The EEG is in both cases dominated by a high voltage $11-12 \mathrm{c} / \mathrm{s}$ responsive alpha rhythm. 4-7 c/s intermediate slow and 1-3 c/s slow frequencies are well represented in both cases. Atypical fast bilateral spike and wave discharges occur frequently in the co-twin's record and less often in the proband's record. The discharges are enhanced in both cases by overbreathing and, in the co-twin, by photic stimulation.

\section{Blood Grouping}

Probability monozygotic on blood grouping + like sex (by Smith and Penrose method 1955)

Finger prints

Total count

Probability monozygotic

on fingerprints (by

Slater method 1963)

$$
\underbrace{\begin{array}{c}
A_{1}, N_{S N}, P_{1}, r r, L u(a-), K+, \quad A_{1}, N_{S N}, P_{1}, r r, L u(a-), K+, \\
\text { Le }(a-b+), F y(a+b+), X g(a+) \quad \text { Le }(a-b+), F y(a+b+), X g(a+)
\end{array}}_{.965}
$$

$\underbrace{189}_{.78} 182$

when her sister won an important beauty competition. It was thought that this was the final stress, in an ongoing state of sibling rivalry, which precipitated her illness. She eventually recovered spontaneously and is now engaged to be married. In the second case (Willis 1965) the proband is said to have become ill at the time when her sister became engaged to be married In both cases the proband was considered to have been "immature" premorbidly and was regarded quite definitely as being the non-dominant member of the twinship.

\section{Case History}

The present report is of an identical twin, whose identical twinship has been established beyond all reasonable doubt (Table 1), and who has suffered from anorexia nervosa in which respect she is discordant with her twin sister. The patient, aged just 22 , was referred by a general physician to whom she had been sent for investigation of her amenorrhoea. Her complaints were 'I'm feeling rather depressed; I've gone off potatoes, bread and things, although I still feel hungry; I sleep poorly".

She was born in December 1940, the first of identical twins. The labour was uncomplicated. At birth the patient weighed $5 \mathrm{lb} .4 \mathrm{oz}$. and her sister weighed $5 \mathrm{lb}$. $0 \mathrm{oz}$. She described her mother as an affectionate but tense irritable person, given to periods of silence lasting several days if offended by the patient or her father. A maternal aunt was described as an "alcoholic" and the maternal grandmother was said to be given to bouts of depression. She described her father, a prosperous stock-broker, as a shy, unaffectionate man. There was no family history of undue obesity, leanness or unusual feeding habits. She said that her mother had frequently told her that, on learning late in pregnancy that she was going to have twins, she felt "she could not cope with more than one child without the support of Daddy". The father was away in the Armed Forces from 1940-1944. Neither twin was breast fed, the reason given being that there was insufficient maternal milk. The patient had always been regarded as the more passive and submissive of the twins. The patient's earliest memories were of the house being bombed and of her recurrent illnesses, mainly "colds" and "bronchitis", which interfered with her schooling. The twin sister more often evoked criticism and punishment from the parents and was perceived by the patient as being jealous of the patient's frequent absences from school which enabled her to be at home with her mother. The patient said that her father had never shown any overt affection to either of them since his return to the home when they were aged 4 years.

Both twins were well nourished during childhood. During this time they both bit their nails excessively and the patient described herself as having been "pretty highly strung". She recalled that she had always been very anxious and shy in company and panticularly distressed and anxious to "cover up" for her sister when the latter was under criticism. When the patient was aged 11 the mother developed pulmonary tuberculosis and spent some months in hospital. During this time the patient recalled that she 
TABLE 2

\begin{tabular}{|c|c|c|c|c|}
\hline Test & \multicolumn{3}{|c|}{ Proband } & Co-Twin \\
\hline \multirow[b]{2}{*}{$\begin{array}{l}\text { Chest X-Ray } \\
\text { Haemoglobin } \\
\text { WBC Total } \\
\text { Differential-neutrophils } \\
\text { - - lymphocytes } \\
\text { - monocytes } \\
\text { - eosinophils }\end{array}$} & \multicolumn{2}{|c|}{ Before treatment } & After treatment & \\
\hline & $\begin{array}{l}\text { Normal } \\
98 \% 14.2 \mathrm{~g} . \% \\
4,600 / \mathrm{cu} . \mathrm{mm} . \\
67 \% \\
30 \% \\
2 \% \\
1 \%\end{array}$ & & $\begin{array}{l}81 \% \quad 11.8 \mathrm{~g} . \% \\
6,600 / \mathrm{cu} . \mathrm{mm} . \\
72 \% \\
19 \% \\
9 \%\end{array}$ & \\
\hline $\begin{array}{l}\text { ESR } \\
\text { Augmented Histamine Test } \\
\text { for gastric acidity }\end{array}$ & $\begin{array}{l}2 \mathrm{~mm} . / \mathrm{lst} \text { hour } \\
\frac{\text { Free HCl. ml. }}{\frac{\mathrm{N}}{10} \%}\end{array}$ & Vol. ml. & $8 \mathrm{~mm} . / \mathrm{lst}$ hour & \\
\hline $\begin{array}{l}\text { Resting Juice } \\
1 \text { hour before histamine } \\
1 \text { hour after histamine }\end{array}$ & $\begin{array}{r}3 \\
19 \\
117\end{array}$ & $\begin{array}{l}10 \\
63 \\
55\end{array}$ & & \\
\hline $\begin{aligned} \text { S. Electrolytes- } & -\mathrm{Cl} \\
-\mathrm{K} & -\mathrm{Na}\end{aligned}$ & $\begin{array}{l}99 \mathrm{mEq} / 1 \\
4.6 \quad " \\
146 \Rightarrow\end{array}$ & & $\begin{array}{l}96 \mathrm{mEq} / 1 \\
4.2 \% \\
150 \%\end{array}$ & $\begin{array}{l}97 \mathrm{mEq} / 1 . \\
5.1 \% \\
145 \Rightarrow\end{array}$ \\
\hline $\begin{array}{l}\text { Blood-Urea } \\
\text { S. Cholesterol } \\
\text { S. Magnesium }\end{array}$ & $\begin{array}{l}51 \mathrm{mg} . / 100 \mathrm{ml} . \\
400 \% \\
2.1\end{array}$ & & $\begin{array}{l}41 \mathrm{mg} . / 100 \mathrm{ml} . \\
350 \% \\
2.1\end{array}$ & $\begin{array}{l}36 \mathrm{mg} . / 100 \mathrm{ml} . \\
270 \quad, \\
2.2 \quad,\end{array}$ \\
\hline $\begin{array}{r}\text { Blood Proteins - total } \\
\text { - albumen } \\
\text { - globulin }\end{array}$ & $\begin{array}{ll}6.6 \mathrm{~g} . / 100 \mathrm{ml} \\
4.0 & \Rightarrow \\
2.6 \quad "\end{array}$ & & & $\begin{array}{l}7.1 \mathrm{~g} / 100 \mathrm{ml} \\
4.2 \\
2.9 \mathrm{~g}\end{array}$ \\
\hline Electrophoretic pattern & Normal & & & Normal \\
\hline BMR & $-18 \%$ & & $-1 \%$ & $+2 \%$ \\
\hline $\begin{array}{l}\text { Gastric Motility } \\
\text { (Telemetering pill) } \\
\text { Random blood sugars }\end{array}$ & $\begin{array}{l}\text { Normal } \\
68 \mathrm{mg} . / 100 \mathrm{ml} \text {. (me } \\
13 \text { samples) }\end{array}$ & an of & Normal & \\
\hline $\begin{array}{r}\text { Oral GTT }- \text { Fasting } \\
-30 \mathrm{~min} . \\
-60 \mathrm{~min} . \\
-90 \mathrm{~min} . \\
-120 \mathrm{~min} .\end{array}$ & $\begin{array}{rl}55 & \mathrm{mg} . / 100 \mathrm{ml} . \\
101 & " \\
140 & " \\
101 & " \\
75 & "\end{array}$ & & & 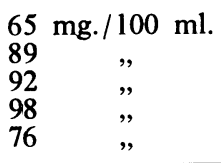 \\
\hline
\end{tabular}

became increasingly aware of disharmony between her parents and of her father's temporary attachment to a younger woman. Subsequently the threat of separation between her parents increased and the mother is said to have used her daughter as a confidante, discussing her own frigidity, her disgust with sexual matters, her husband's tendency to be "oversexed" and his inability to provide any emotional support in the home. She is said frequently to have told the twins at this time that it was only they who prevented her from leaving her husband.

The patient reported her menarche as having occurred at the age of 14 years and 3 months and her sister's at the age of 12 years and 6 months. This was confirmed by the parents. The twins were initially privately educated and then, at the age of 11 , they went as day pupils to a Roman Catholic Girls Public School. Around this time the patient began to feel bewildered by the increasing social demands imposed on her. She began to mimic her twin in their joint social activities. She became afraid of answering the telephone. Both twins did well at sport and became expert horsewomen. School contemporaries of the twins have reported that they found the proband a "kind, sweet, friendly person" and her sister "a more irritable, egocentric person". The patient unexpectedly gained only 4 " $O$ " levels in the G.C.E. Her sister gained 6 " $O$ " levels.

At the age of 13 the patient had a "crush" on a local boy but became frightened by his demands on her to kiss and cuddle him. She withdrew from the relationship. Around the age of 17 her sister became more interested in boys and began to go out on her own. The patient determined to show a similar interest and became friendly with a 17-year-old boy. He began to make physical sexual demands upon her and she felt "disgusted" and "unmoved". The mother recalled that at this time she was plump. The patient denied this at interview. She recalled that she began to feel she could not eat potatoes and puddings when in her boy friend's house. Shortly afterwards she gave up this boy friend. She also began at times to abstain from meals at home when her sister was not there, particularly if her parents 
TABLE 3

Glucose Tolerance and Insulin Response to Intravenous InJection of 25 g. Glucose (Proband)

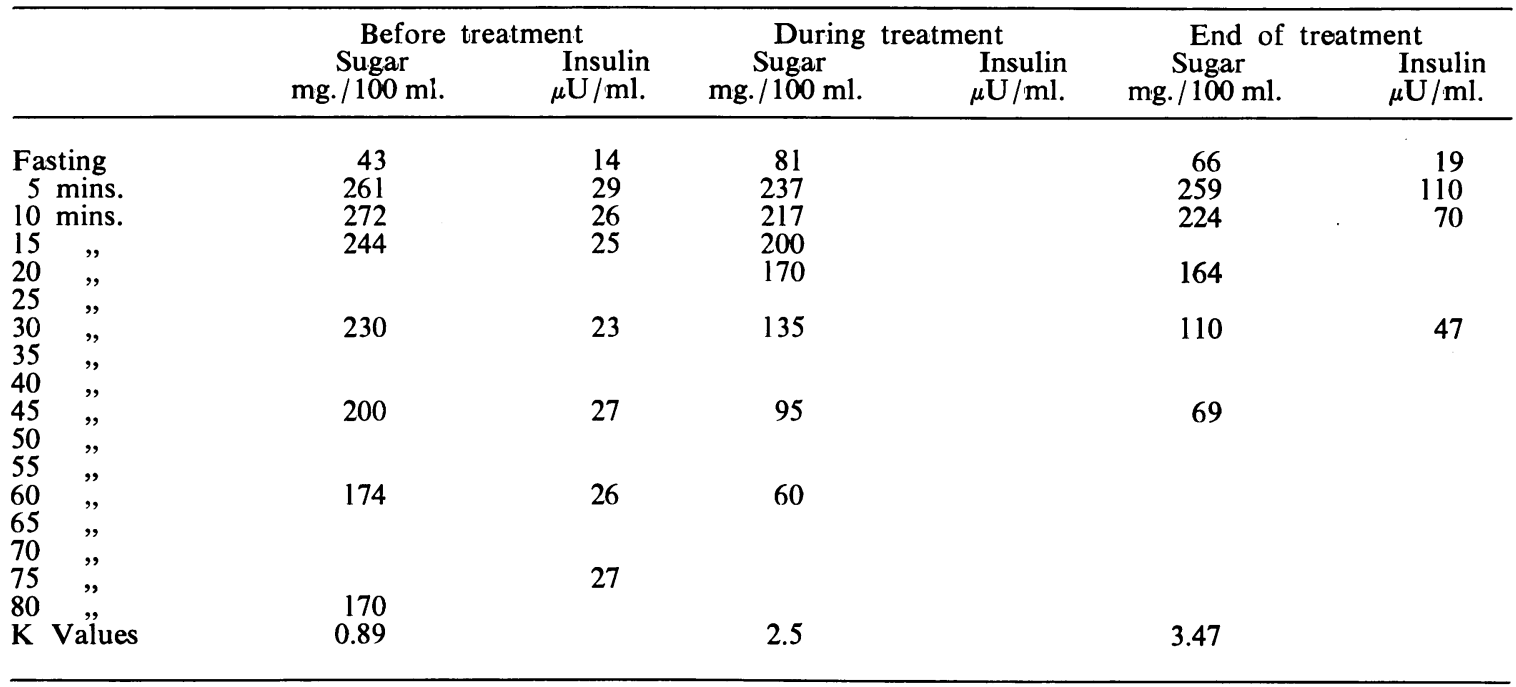

were quarrelling. She became increasingly depressed. She and her sister remained united in their joint and increasingly devoted interest and activities within an authoritarian and evangelical section of the Church. The parents resented this particular interest and frequent quarrels ensued over the twins' attempts to convert them.

After leaving school she spent 6 months at home and then started a secretarial training. At the age of 18 she underwent appendicectomy; a normal appendix was found. Subsequently she embarked upon a nursing training for 6 months but felt "homesick" and abandoned it. A second attempt at nursing training also failed although she did particularly well in her preliminary training. At this stage she was referred to a psychiatrist with complaints of depression and some slight weight loss. She attended for a few interviews. Subsequently she became slightly less depressed and regained some weight. The patient was now 20 years old. Her sister became friendly with a man and announced to the patient her intention to marry him. The patient recalled that at this time she determined to diet systematically "because I intended taking a secretarial job which would be sedentary". Amenorrhoea supervened within 2 months of her starting to diet and before there was any noticeable weight loss. During the next 18 months the patient lost weight steadily from 8 st. down to 6 st. She found that she was now somewhat less depressed and that "My feelings aren't hurt so much now". She found it was increasingly difficult to sleep and in particular began to wake early in the morning. She became preoccupied with her weight and with daily weighing; she began to experience anxiety and guilt if there was any weight gain and relief if there was none. She became excessively interested in cooking and preparing food for her parents. She consistently refused to eat any reasonable quantity of carbohydrate. She became increasingly orderly, conscientious and concerned over cleanliness, also more sensitive and prone to periods of silence. She became increasingly active and concerned to exercise herself with long walks. She continued to work satisfactorily and was free from intercurrent illness. At this point she was referred to hospital.

During the initial interview with the parents, their incompatibility became apparent; also their common concern for the patient's health.

The mother, when seen alone, described her husband as a most dependent, unaffectionate man who had seemed jealous of her relationship with the twins from the time that he returned home after the war. She contemptuously described his frustrated sexual needs in relation to herself and disclosed that he frequently "eyed" adolescent girls and that on one occasion he had narrowly avoided being charged with importunate behaviour on a railway train. She and the patient denied that he was attracted to the patient in this way or that the patient had ever attempted to evoke affection from him by behaving seductively towards him. Such behaviour, however, emerged later as a transference phenomenon!

The father described his wife as an embittered domineering person who had suffered an unhappy childhood and who had subsequently battled against many difficulties of a physical and emotional kind in her married life. He confirmed the account of his wife's frigidity.

The twin sister, who expressed and revealed considerable feelings of guilt about her sister's illness, gave an account of the family background which was similar to the patient's account. The twin sister has remained in a normal physical, nutritional and dietary state throughout her life and has never sought psychiatric help. Her weight has been steady at about 9 st. since her mid-teens.

On Examination: Mental State. Simply dressed, carefully and modestly toileted, submissive, child-like in posture, manner and voice. Mood-at times responsive and smiling; at other times quiet and still; tearful when discussing the ways in which she is sometimes compelled by others to eat. Expressing ideas of hopelessness; that she will never be normal, will never marry and will end up by killing herself. 
Admits to being preoccupied with thoughts of food and with a fear of gaining weight.

Physical Examination. Emaciated girl; relative retention of breast fat. Weight 5 st. 12 lb. B.P. $90 / 65$ $\mathrm{mm}$. Hg. Pulse rate $56 / \mathrm{min}$, regular. Body temperature $96^{\circ} \mathrm{F}$; cold blue extremities. Downy hair over shoulders and back.

\section{Investigations. Table 1: Zygosity Data.}

Tables 2 and 3: Other Investigations.

Treatment. The patient was put to bed and established on chlorpromazine $100 \mathrm{mg}$. t.d.s. and a refeeding regime (Crisp, 1966). Psychotherapy was started and has since continued on a once-weekly basis (120 sessions). The patient gained weight up to $7 \frac{1}{2}$ st. over the period of the first 6 weeks. At this point her twin sister married. The patient attended the wedding and behaved histrionically. Immediately afterwards she insisted on leaving hospital and going home permanently. She anticipated spending several months at home with her mother alone. Within a few days the patient was quarrelling with her mother and refusing to eat. She became depressed and lost weight. She was re-admitted to hospital. Antidepressant drugs (imipramine $50 \mathrm{mg}$. t.d.s. and, later, phenylzine $15 \mathrm{mg}$. t.d.s.) were given for adequate periods of time and did not lead to any improvement. However, the patient claimed that perphenazine 4 mg. t.d.s. relieved her of tension feelings. The patient spent 4 months in hospital. If allowed home for week-ends she would either abstain from eating or, when she visited her twin sister, she would overeat. She became gradually less depressed whilst in hospital and was encouraged to take up temporary secretarial work. On discharge from the hospital she returned home. During the next 2 months she worked fairly well. She began to take an interest in social activities but felt very anxious when she attended one or two parties and was not able to participate in the general conversation and dancing. At this point her mother started drinking alcohol excessively, having been a moderate daily social drinker for many years. The mother attributed this increased drinking to the stresses imposed on her by the major rows which were now occurring frequently between the patient and her father. Her father was reported on as becoming increasingly impatient and irritable with the patient. She was obviously anxious at this time to spend as much time with him as possible. The patient began to lose weight and again gave up work. She then made two successive suicidal attempts which were ineffectual in their probably main intent to alter the parental attitudes towards her and towards each other. The parental attitudes remained those of apparent concern for her but the mother was becoming increasingly exasperated. The patient ate nothing for 10 days and was re-admitted to hospital in a state of collapse. She remained in hospital for the next 11 months. Initially she underwent a course of modified insulin treatment. This was associated with increased food intake in the mornings and some weight gain, but her eating behaviour became more unstable, with bouts of bulimia leading to anxiety and depression followed by one or two days of total abstinence from eating. During one of the hypoglycaemic episodes induced by the insulin she developed a grand mal seizure (consistent with demonstrated EEG vulnerability). Overall the patient remained depressed. A course of 13 ECT was not associated with any improvement.

Psychotherapy continued and the patient was be- ginning to express intense feelings of hostility towards her sister and her mother. She also began to increasingly express an awareness of her unsatisfied needs for affection and security in relation to her parents. It became clear, from several informants, that the twin sister was egocentric and had often interfered with the patient's few feeble attempts to develop other relationships by taking them over herself. It emerged that the twin sister's husband had originally met and shown some benevolent interest in the patient but that the twin had "stolen" him. The patient developed an intense dependence upon the ward staff and on several other patients. She remained child-like in her manner and speech. She developed a dependent and flirtatious attachment to the therapist which was regarded as a direct "transference" from her relationship with her father and progressively interpreted as such. She slashed her wrists, inflicting venous bleeding, on several occasions during this period of several months. This behaviour was regarded as acting out behaviour within the "transference" and interpreted as such. She was eventually told that she must not repeat this behaviour if she wished to remain in therary. The behaviour ceased. It was not until some intensive psychotherapy was done with the parents however that she began to improve. The mother had been in individual psychotherapy, occurring once every few weeks, for about 10 months. She had remained resistant to being involved in the treatment process. Now the therapy was conducted jointly with both parents together with a therapist. The father was able to discuss his own feeling of inadequacy and his sense of rejection for the first time ever with his wife in these sessions. Subsequently he was able to adopt a more positive role in the family. The patiente was able to spend several week-ends at home. She began to eat more normally and slowly gained weight over the next 2 months. Menstrual bleeding recommenced. It became apparent that it would be better for her to live away from home for the most part, if a suitable protective milieu could be found. This proved possible and the patient was discharged from hospital. She continued to have similar emotional difficulties from time to time and remained obviously dependent on those around her. However her feeding behaviour became less sensitive to these difficulties and she was less depressed. She made one more suicidal gesture when her twin sister went into labour. She was subsequently able to recognise this as being in part a hostile act against her sister. Psychotherapy is continuing. Regular monthly menstrual bleeding has now been present for the last 9 months. Her weight remains fairly steady at around 9 st.

\section{Discussion}

A case of anorexia nervosa in a female identical twin is reported. The probability (based on zygosity data) that these twins are other than monozygotic is so small that it can be ignored. The case history, taken from the patient and other informants, together with further exploration and psychotherapy, suggests that the patient has always been the more passive and submissive of the twins; furthermore that her feelings of anxiety, sensitivity and insecurity were intensified around the age of 13 and 14, at the time of her menarche and also at the time when her fears of disharmony and threat of separation between her 
parents became increasingly confirmed. At this time her mother used her as a confidante in describing her father's inadequacies and his "excessive" sexual demands unaccompanied by interest in or support for the family. There was some evidence that the father's behaviour at this time was a reaction to his wife's earlier neurotic rejection of him. The patient intensified her lifelong attempt to evoke, to her own satisfaction, demonstration of affection by her father towards herself. She failed. In this situation the patient came to increasingly rely upon and mimic her twin sister, feeling that she (the patient) had no separate identity. By this she meant that, providing she stayed with her sister and imitated her behaviour, she remained apparently socially competent. If required to act alone, however (e.g. to answer the 'phone) she would feel panic and usually withdraw from the situation. She succeeded in this behaviour until her sister, with whom she had a complex and intensely ambivalent relationship, began to develop separate heterosexual interests. The patient's attempts to follow suit in seeking affection outside the home and to lead a similar independent life were associated with feelings of isolation, panic and digust. As the threat of separation between her parents became more imminent the patient abandoned all attempts at developing peer relationships. She became increasingly depressed and at the same time began to avoid meals and in particular their carbohydrate content. At the time when her sister's engagement to be married became imminent the patient developed severe anorexia nervosa. This illness, which was associated with cessation of what had been tentative but frightening postpubertal activities for her and during which she was also able to relinquish her close relationship with her twin sister without expressing her hostile feelings and without feeling as distressed as she had anticipated she would, also led to her being thrust back into an unsatisfying and increasingly neurotic relationship with her parents. However, the mother's earlier threat to leave the home did not materialize and the patient now believes that her illness has had the effect of preventing her parents separating from each other.

Psychotherapy was directed toward the patient and her parents. It was concerned to enable the family to communicate with each other more freely and directly, particularly over matters concerning their own interrelationships and individual needs and feelings towards each other. Efforts were also made to help the patient, mainly by interpretation of the 'transference' and of other 'here and now' behaviour and also by encouraging her to undertake social activities within the therapeutic milieu. This was associated with slow progress and the patient eventually came more easily to be able to dissociate her feeding behaviour from her emotional conflicts. The latter have persisted until the present time but she is now more able to cope with them.
The ways in which such conflicts may come, in anorexia nervosa, to involve feeding behaviour has been discussed elsewhere. In this patient, her birth weight was $\frac{1}{4} \mathrm{lb}$. more than her sister's. This discrepancy, though small, is in the same direction as the significant discrepancy between the main group of patients and their sister siblings (Crisp, 1965ib). In the present case it presumably reflects differences in intrauterine nutrition of a nongenetically determined kind. During childhood both twins were well nourished although the patient was regarded as more 'faddy' than her sister. The patient's menarche is reported on as having occurred later than her sister's. This finding is not typical of the main group of patients. Furthermore, this reported discrepancy between the twins' menarches of 1 year and 9 months is a much greater one than that usually found in identical twins (Tanner, 1962). During the two or three years following her menarche the patient is reported on by her mother as having been somewhat plumper than her twin sister but the patient denies this.

Investigation of glucose tolerance in the healthy twin and in the patient before treatment showed differences between the twins in their response to $50 \mathrm{~g}$. oral glucose. The normal twin showed a more normal response consistent with that often found in healthy young people. The proband, both in response to $50 \mathrm{~g}$. oral glucose and later, 25 g. i.v. glucose, produced a high and somewhat delayed response. This may have been due to defective utilization (Crisp, 1965b) or else to differences in the glucose space between the twins. Such a response is a characteristic finding towards normal (reflected in increasing $\mathrm{K}$ values) in starvation and, in the proband, it returned on refeeding. However, the insulin response of the proband to an intravenous injection of $25 \mathrm{~g}$. glucose both before and after treatment showed a sustained type of response which has elsewhere been shown (Crisp, 1965b) to be a characteristic of a group of anorexia nervosa subjects in which respect they were different fnom normals. Furthermore, two of the anorexia nervosa subjects in this latter study showed the same type of response one year after full clinical recovery from their illnesses.

The patient's BMR was characteristically low before treatment and returned to within normal limits following weight gain and restoration of menstrual bleeding. This patient almost certainly did not vomit or purge herself excessively and the majority of the blood tests carried out have provided predictably normal results although the relatively high haemoglobin and blood urea before treatment compared with after treatment suggests that there was some initial dehydration present. However, the patient's serum cholesterol was substantially raised before treatment and was somewhat lower at the end of treatment. This has been a common finding amongst the total patient group. It may reflect to some extent the large quantities of cheese that this patient, 
like the majority of patients, ate while ill; also be related to the infrequency of her meals (Fabry, Fodor, Hejl, Braun and Kamila, 1964).

\section{Summary}

A case of anorexia nervosa in a confirmed identical twin is reported. The proband is discordant with her twin sister for the illness. It is suggested that the predeterminants of anorexia nervosa are predominantly environmental. Thus, despite their identical genetic endowment these twins were regarded as different in personality from an early age (a common finding with identical twins, Parker, 1964). Equally, their nutritional status, which was probably already different at the time of birth, has remained slightly different. It is suggested that these possibly interrelated premorbid factors may have predisposed the patient to develop anorexia nervosa when confronted by adolescent conflicts. Thus, the patient's life-long feelings of insecurity, which ill-prepared her for an adult independent life, were intensified around the age of 17 when her parents threatened to separate from each other while at the same time her twin sister began to develop independent interests. The patient, with her intense social anxiety, equally intense need for affection together with her disgust of 'sex' (the latter possibly engendered by her mother's attitude to her own marriage) was unable to find suitable heterosexual peer relationships. The patient's illness may be regarded as a disorder of nutrition which has been associated with avoidance (biologically and socially) of further postpubertal activity, whilst her persistent inability to eat and her childlike behaviour has been associated with enhanced and exclusive dependency on her parents who in fact have not separated. Her new-found and now almost immutably dependent relationship with her parents had become an increasingly neurotic one. Psychotherapy, directed towards the patient and the parents, has been associated with gradual recovery of the patient, who is now rather belatedly, but more confidently, retesting out her 'adolescent' life situation At present she is less prone to use abnormal feeding behaviour in her attempts to resolve recurring anxieties arising in this situation.

The author wishes to express his gratitude to Professor Denis Hill, under whose care the patien is, for his help and advice, Miss M. Bailey? P.S.W., and Dr. Eugene Wolf, who conducted the therapy with the parents; also Dr. N. Parker and Mr. J. Shields of the Psychiatric Genetics Researckp Unit, Maudsley Hospital, London, S.E.5, and Dr. Rत् Sanger of the Blood Group Research Unit, Liste? Inst., Chelsea Bridge Road, London, S.W.1, for theite help with the zygosity determinations.

\section{REFERENCES}

Bliss, E. L., and BRANCH, C. H. (1960): Anorexia Neryosa, New York: Paul B. Hoeber.

CRISP, A. H. (1965a): Clinioal and Therapeutic. Aspects of Anorexia Nervosa: a Study of $30 \mathrm{~V}$ Cases, J. psychosom. Res., 9, 67.

CRISP, A. H. (1965b): Some Aspects of the Evolution Presentation and Follow-up of Anorexia Nervosao, Proc. roy. Soc. Med., 58, 814.

CrisP, A. H. (1966): A Treatment Regime for Anorexia Nervosa, Brit. J. Psychiat. In press.

Fabry, P., FoDOR, J., Hejl, Z., BRaun, T., and Zvolankova Kamila (1964): The Frequency of
Meals, Lancet, ii, 614.

KING, A. (1963): Primary and Secondary Anorexia Nervosa Syndrome, Brit. J. Psychiat., 109, 470.

MEYER, J-E. (1961): Das Syndrom der Anorefora Nervosa, Archiv. Psychiat. Nerdenkr., 202, 31. 응

PARKER, N. (1964): Close Identification in Twîns Discordant for Obsessional Neurosis, Brit. 107.0
Psychiat., 110, 496.

RUSSELL, G. F. M. (1964): Psychological Factors in the Control of Food Intake in 'Diet and Bodilyo Constitution', Ciba Foundation Study Group No. 17, 69-89. London: J. \& A. Churchill.

RuSSELL, G. F. M. (1965): Metabolic Aspects of Anorexia Nervosa, Proc. roy. Soc. Med. In press. $\overrightarrow{0}$

SLATER, E. (1963): Diagnosis of Zygosity by Finger- 3 prints, Actä psychiat. scand., 39, 78.

SMITH, S. M., and PENROSE, L. S. (1955): Mono-局 zygetic and Dizygotic Twin Diagnosis, Ann. hum.

Genet., 19, 273 .
TANNER, J. M. (1962): Growth at Adolescence, Oxford: Blackwells.

TIBBETTS, R. W. (1965): personal communication Willis, J. H. (1965): personal communication. 